IMECE2017-70392

\title{
HEXAFLY-INT EXPERIMENTAL FLIGHT TEST VEHICLE (EFTV) AERO-THERMAL DESIGN
}

\author{
Roberto Scigliano \\ Italian Aerospace Research Centre (CIRA) \\ Capua, Italy
}

\author{
Giuseppe Pezzella \\ Italian Aerospace Research Centre (CIRA) \\ Capua, Italy
}

\author{
Johan Steelant \\ European Space Agency (ESA) \\ Noordwijk, The Netherlands
}

\author{
Sara Di Benedetto \\ Italian Aerospace Research \\ Centre (CIRA) \\ Capua, Italy
}

\author{
Marco Marini \\ Centre (CIRA) \\ Capua, Italy
}

\section{ABSTRACT}

Over the last years, innovative concepts of civil high-speed transportation vehicles were proposed. In this framework, the Hexafly-INT project, funded by European Commission by means of $7^{\text {th }}$ Framework Programme, intends to test in freeflight conditions an innovative gliding vehicle with several breakthrough technologies on-board. This approach will help to gradually increase the readiness level of a consistent number of technologies suitable for hypervelocity flying systems. The vehicle design, manufacturing, assembly and verification is the main driver and challenge in this project. The prime objectives of this free-flying high-speed cruise vehicle shall aim at a conceptual design demonstrating a high aerodynamic efficiency in combination with high internal volume; controlled level flight at a cruise Mach number of 7 to 8; an optimal use of advanced high-temperature materials and structures. Present research describes the aero-thermal design process of the Experimental Flight Test Vehicle, namely EFTV. The glider aeroshape design makes maximum use of databases, expertise, technologies and materials elaborated in previously European community co-funded projects LAPCAT I \& II [1][2], ATLLAS I \& II [3][4] and HEXAFLY [5]. The paper presents results for both CFD and Finite Element aero-thermal analysis, performed in the most critical phase of the experimental flight.

In this framework, three-dimensional steady state fully turbulent CFD calculations have been carried out at several flight points along with a reference design trajectory and for radiative cooled wall boundary conditions for the glider. This numerical campaign allowed defining the aerothermal loading environment the flying test bed has to withstand during mission, such as the convective heat flux distributions on EFTV aeroshape to feed the subsequent thermal analyses. These
\end{abstract}

analyses have addressed a proper material selection. Different classes of materials have been preliminarily selected and analysed for the EFTV structure, namely: titanium alloy, copper, $\mathrm{C} / \mathrm{C}-\mathrm{SiC}$ and zirconia for surface coatings. Titanium alloys exhibit a unique combination of mechanical and physical properties and corrosion resistance, which have made them desirable for critical, demanding aerospace applications, also in high temperatures conditions. Copper is employed as a heat sink to accommodate the thermal energy in some critical components such as the nosetip. $\mathrm{C} / \mathrm{C}-\mathrm{SiC}$ developed at DLR is considered for ailerons and for the wing leading edges. A zirconia coating layer has been also considered to protect metallic components.

\section{NOMENCLATURE \\ $Y^{+} \quad=$ non-dimensional wall distance \\ $M_{\infty} \quad=$ free-stream Mach number \\ $\varepsilon \quad=$ surface emissivity \\ $R e_{\infty} \quad=$ free-stream Reynolds number \\ $\Lambda=$ wing sweep angle \\ $H_{0} \quad=$ total enthalpy \\ EFTV $=$ Experimental Flight Test Vehicle \\ $\mathrm{FE} \quad=$ Finite Element}

\section{INTRODUCTION}

The Experimental Flight Test Vehicle (EFTV) shown in Figure 1 is a hypersonic glider of $3.29 \mathrm{~m}$ long and with a wing span of about $1.23 \mathrm{~m}$. The EFTV has a two-dimensional nosetip with $2 \mathrm{~mm}$ rounding and $2 \mathrm{~mm}$ lateral fillet, while the wing is characterized by a $80 \mathrm{deg}$ sweep angle and $14 \mathrm{deg}$ negative dihedral angle, and $1 \mathrm{~mm}$ rounded leading edge. The vehicle is 
equipped by a couple of active ailerons ( $0.4 \mathrm{~m}$ long and $0.32 \mathrm{~m}$ wide), which can be deflected in symmetric and asymmetric way, and a couple of fixed vertical fins for passive lateraldirectional control characterized by a $68.5 \mathrm{deg}$ sweep angle and a 54 deg canted fins.

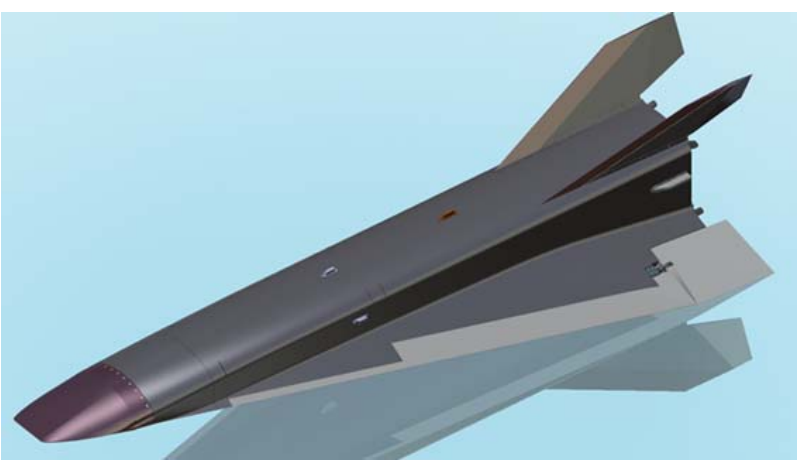

Figure 1. EFTV aeroshape.

The present aeroshape of the EFTV is the result of an evolution, fully described in Ref. [1]. A detailed focus on Hexafly-INT mission details and goals can be found in Ref. [7].

\section{FLIGHT TRAJECTORY}

The preliminary mission trajectory, shown in Figure 2, was generated by DLR-Moraba considering the VS43, as launch vehicle, and a total payload mass of $800 \mathrm{~kg}$ (i.e. EFTV, ESM, launch vehicle service module, and launcher fairing). Starting form the apogee at $90 \mathrm{~km}$ altitude, Gas Dynamics Ltd. (GDL) evaluated the descent trajectory for both the train vehicle, namely EFTV+ESM, and the EFTV alone, after the separation from ESM. The end of mission is assumed at $20 \mathrm{~km}$ altitude [1][8].

This flight mechanics analyses rely on an inviscid aerodynamic database generated by CIRA for the train and by DLR-Braunschweig for the EFTV [1],[9],[10]. Viscous effects on EFTV aerodynamics were provided by GDL [1].

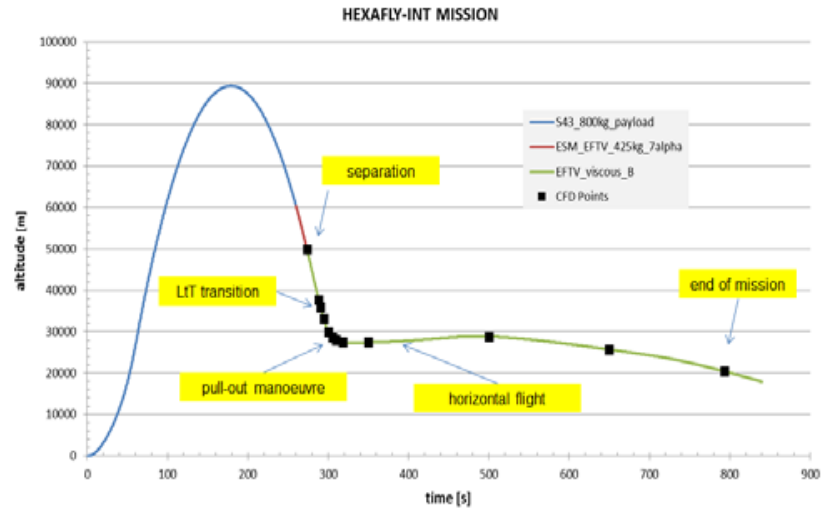

Figure 2. Altitude time history. Complete flight profile.
The hypothesis of continuum regime was verified for the last two phases of flight trajectory [1],[9]. After an analysis of the train trajectory, from $60 \mathrm{~km}$ to $50 \mathrm{~km}$, the separation of EFTV from ESM was assumed at $50 \mathrm{~km}$ altitude where typical control authority criteria were satisfied. In particular, separation was calculated to occur at the following conditions: $49.94 \mathrm{~km}$ altitude, Mach=7.07, AoA=6.83 deg, flight path angle of -20.53 $\mathrm{deg}$, in a condition of natural trim for the descending "train" for zero sideslip. For the glider trajectory calculation, GDL assumed an EFTV mass of $350 \mathrm{~kg}$ and its centre of gravity coinciding with the moment reference centre $(1.455,0.0,0.12)$ [m], i.e. at $57 \%$ of the glider full length. EFTV's AoA initial schedule was based on a profile defined by CIRA that satisfies control authority criteria. GDL generated a number of 3 degree of freedom planar trajectories for the hypersonic glider considering turbulent viscous effects estimated by an engineering conservative approach, and with a limited level of optimization. Trajectory B-viscous was finally selected as reference having the longest duration and the highest mission parameters during the experimental phase of flight, namely Phase I, i.e. $L / D \geq 4$ with $M_{\infty} \geq 7$. This trajectory is the green leg in Figure 2, starting from $50 \mathrm{~km}$ altitude. Even though less performing for the remaining phase of flight, namely Phase II, trajectory B-viscous was considered as the lower reference trajectory of the flight corridor as it has a built-in margin during future trajectory consolidation, and it is adopted as reference for the thermo-structural analysis. Any future optimized trajectory will not need questioning whether the EFTV will be not affected along it w.r.t. structural and thermal loads [8].

\section{AEROTHERMODYNAMIC CALCULATIONS}

The assessment of the aero-thermal loading environment the EFTV glider has to withstand during mission relied on both engineering-level and CFD-based analyses. For instance, the time history of convective heat flux at aeroshape stagnation point corresponding to the trajectory B-viscous is shown in Figure 3, where the altitude profile (the green curve) is provided as well. This aeroheating profile, obtained through the Zoby relationship for radiative cooled wall and constant specific heat at constant pressure $c_{p}$,

$$
\dot{q}_{0}=3.88 * 10^{-4} \sqrt{\frac{p_{t^{2}}}{R_{N}}\left(H_{0}-h_{w}\right)}
$$

was the starting condition for the EFTV aerothermal design [11].

Indeed, the stagnation point heat flux allowed determining the convective heat transfer coefficient (see Figure 4)

$$
h=\frac{q_{0}}{\left(T_{0}-T_{w}\right)}
$$


needed to feed the aeroshape thermal analysis, as discussed later, and the peak heating conditions expected during the flight.

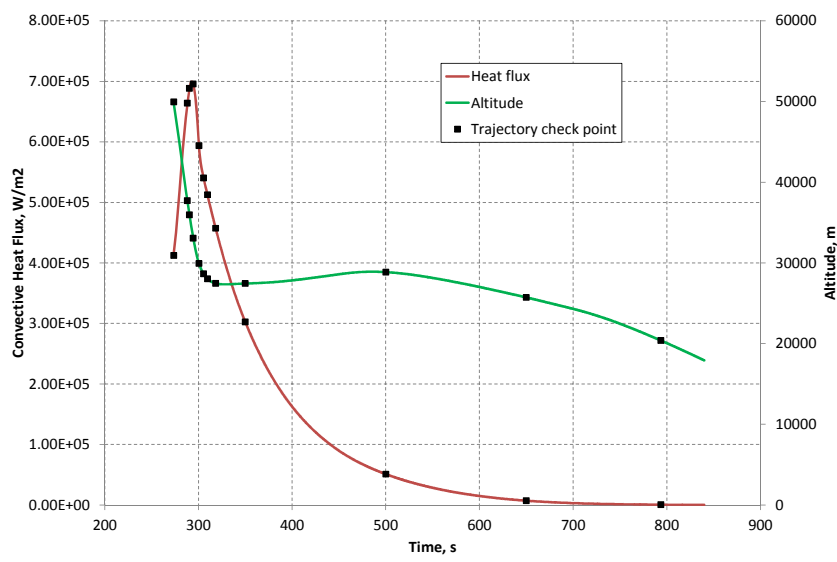

Figure 3. Altitude and convective heat flux time histories for the trajectory B-viscous.

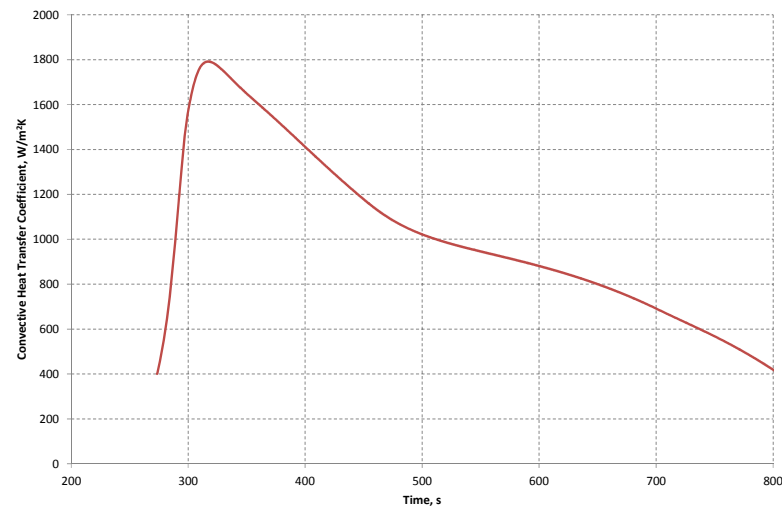

Figure 4. Time history of the convective heat transfer coefficient for the trajectory B-viscous.

In a step-by-step approach, this punctual assessment was completed by more detailed surface distribution of aerothermal loads through CFD analyses carried out at certain critical flight conditions (see black full squares displayed in both Figure 2 and Figure 3) sampled on the B-viscous reference design trajectory, according to the trajectory-based design approach [12]. Indeed, three-dimensional steady state CFD calculations have been carried out at several flight points, namely check points, chosen in such a way to fully reconstruct the time histories of convective heat flux and integrated heat load, expected for the experimental flying test bed during mission, see Figure 3. In particular, as discussed in Ref. [1], those points also correspond to critical sizing events (see Figure 2) such as ESM/EFTV separation; maximum Mach number $\left(\mathrm{M}_{\infty}=7.5\right)$; maximum stagnation-point heat flux; possible laminar-toturbulence transition; maximum angle of attack, maximum a/g, largest (negative) aileron deflection; pull-out manoeuvre; maximum L/D; maximum dynamic pressure (and Reynolds number); horizontal hypersonic flight/gliding flight; end of mission at about $\mathrm{M}_{\infty}=2$.

The detailed content of CFD test matrix carried out by CIRA is reported in Table 1.

\begin{tabular}{c|ccccccc}
$\begin{array}{c}\text { Run } \\
\text { ID }\end{array}$ & $\begin{array}{c}\text { Time } \\
\text { (s) }\end{array}$ & $\begin{array}{c}\text { Altitude } \\
(\mathbf{m})\end{array}$ & $\begin{array}{c}\text { Mach } \\
\text { No. }\end{array}$ & $\begin{array}{c}\text { Aoa } \\
(\mathbf{d e g})\end{array}$ & ReL $_{\mathbf{L}}$ & $\begin{array}{c}\mathbf{H}_{\mathbf{0}} \\
(\mathbf{M J / K g})\end{array}$ & $\begin{array}{c}\mathbf{T}_{\mathbf{0}} \\
(\mathbf{K})\end{array}$ \\
\hline EFTV-065 & 273.50 & 49942.00 & 7.076 & 6.83 & $4.665 \mathrm{E}+05$ & 2.99 & 2981.26 \\
EFTV-066 & 288.14 & 37716.85 & 7.465 & 12.00 & $2.746 \mathrm{E}+06$ & 2.98 & 2963.66 \\
EFTV-067 & 290.39 & 35947.24 & 7.501 & 12.00 & $3.630 \mathrm{E}+06$ & 2.94 & 2930.25 \\
EFTV-068 & 294.44 & 33059.99 & 7.507 & 12.00 & $5.754 \mathrm{E}+06$ & 2.85 & 2836.61 \\
EFTV-069 & 300.52 & 29936.43 & 7.253 & 12.00 & $9.075 \mathrm{E}+06$ & 2.62 & 2608.75 \\
EFTV-070 & 305.49 & 28652.17 & 7.104 & 3.62 & $1.086 \mathrm{E}+07$ & 2.51 & 2497.76 \\
EFTV-071 & 309.55 & 28040.09 & 7.030 & 1.63 & $1.182 \mathrm{E}+07$ & 2.46 & 2444.44 \\
EFTV-072 & 318.37 & 27461.55 & 6.888 & -0.66 & $1.269 \mathrm{E}+07$ & 2.36 & 2349.52 \\
EFTV-073 & 350.00 & 27444.96 & 6.427 & -1.63 & $1.187 \mathrm{E}+07$ & 2.08 & 2074.51 \\
EFTV-074 & 500.05 & 28854.96 & 4.806 & 0.51 & $7.115 \mathrm{E}+06$ & 1.27 & 1266.37 \\
EFTV-075 & 649.95 & 25720.26 & 3.461 & 0.97 & $8.388 \mathrm{E}+06$ & 0.76 & 754.63 \\
EFTV-076 & 793.56 & 20384.69 & 2.002 & 1.31 & $1.142 \mathrm{E}+07$ & 0.39 & 390.89
\end{tabular}

Table 1. CFD Test Matrix.

As discussed in Ref. [13], Table 1 is part of the more extended CFD test matrix considered by ESA, CIRA and TsAGI in order to assess the EFTV viscous aerodynamic database, to verify the EFTV trim conditions along the reference trajectory; to provide mechanical and thermal loads as inputs for thermo-structural analysis of whole EFTV configuration (CIRA, aero-thermal design of EFTV) and some components such as wing leading edge and aileron (DLRStuttgart) and vertical fin (University of Sidney); to provide surface distribution of pressure, heat flux and temperature for the in-flight measurement system design and layout optimization (DRL-Cologne). In particular, numerical simulations have been performed with the hypotheses of fully laminar flow (i.e., run id 065, 066, 067, 068, and 069) and fully turbulent flow (i.e. run ids from 069 to 076). Thus, 13 CFD simulations (i.e. 5 fully laminar and 8 fully turbulent computations) where the Mach number ranges between about 2 and 7 have been addressed. The air was modelled as a continuum ideal gas [8],[13]. Note that, even though CFD simulations have been carried out at hypersonic flow conditions, the ideal gas assumption was still valid. The reason is that the EFTV aeroshape features a very slender configuration (leading edge radius of $2 \mathrm{~mm}$ for nosetip, wings and fins) and shall fly at rather low angle of attack (i.e. weak attached shock waves). Anyway, a temperature-dependent formulation was considered for the specific heat at constant pressure $c_{p}$ (i.e. thermally perfect gas) to accommodate the rather high flow energy. Indeed, the following polynomial formulation for the $\mathrm{c}_{\mathrm{p}}$ was considered:

$$
\begin{aligned}
& c_{p}=5.71 \times 10^{-18} T^{6}-9.79 \times 10^{-14} T^{5}+5.22 \times 10^{-10} T^{4} \\
& -1.27 \times 10^{-6} T^{3}+1.46 \times 10^{-3} T^{2}-5.46 \times 10^{-1} T+1.07 \times 10^{3}
\end{aligned}
$$

where the flow temperature ranges from $100 \mathrm{~K}$ to $2000 \mathrm{~K}$.

For $T<100 \mathrm{~K} c_{p}=1039.59[\mathrm{~J} / \mathrm{kg} / \mathrm{K}]$, while for $\mathrm{T}>2000 \mathrm{~K}$ $c_{p}=1265.35[\mathrm{~J} / \mathrm{kg} / \mathrm{K}]$. Sutherland's relationship was assumed for the dynamic viscosity, while the Spalart-Allmaras oneequation eddy viscosity was accounted for flow turbulence. 
As far as boundary condition is concerned, the radiative cooled wall ( $\varepsilon=0.4$ that is the asymptotic value for $\mathrm{ZrO}_{2}$ coating) was assumed for all the flight conditions with the exception of $\mathrm{M}_{\infty}=2$, where the more appropriate adiabatic temperature boundary condition has been assumed at wall.

The ANSYS-FLUENT ${ }^{\circledR}$ commercial code was used. The Reynolds Averaged Navier-Stokes (RANS) equations are integrated by means of the finite volume approach on hybrid grids (i.e. a domain discretization which uses tetrahedrons in the field and prisms in the boundary layer). The Flux Difference Splitting (FDS) second-order upwind scheme (least square cell based) has been used for the spatial reconstruction of convective terms, while for the diffusive fluxes a cell-centred scheme has been applied. An implicit scheme has been considered for time integration.

For each simulation in Table 1 a dedicated computational grid has been generated by using ICEMCFD ${ }^{\circledR}$ software. To this scope, a watertight simplified EFTV aeroshape (see Figure 5) has been considered by removing the antennas, closing the aileron's hinge line gap and fitting, letting open the aileron's lateral gap.

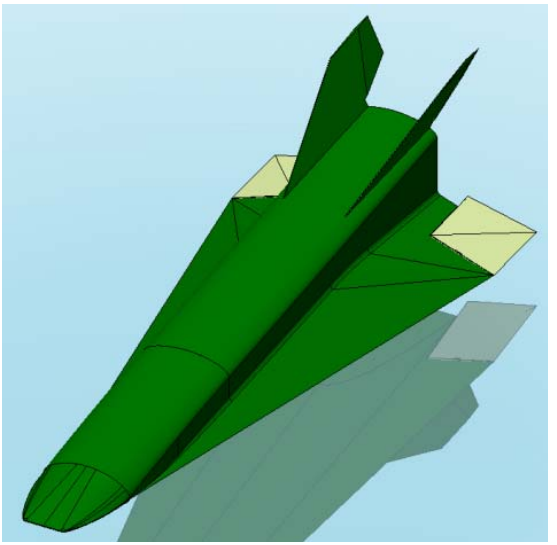

Figure 5. EFTV aeroshape.

A typical CFD computational grid is provided in Figure 6, where the surface mesh on the aeroshape leeside is shown. At least 10 millions of cells were necessary for a half configuration, with the condition of $\mathrm{Y}^{+}=\mathrm{O}(1)$ at wall.

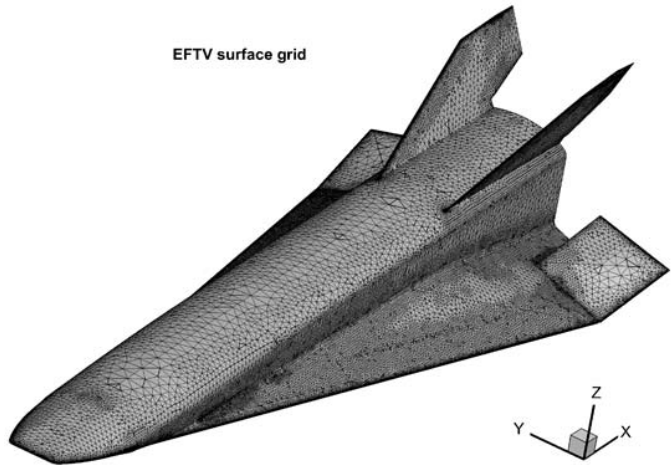

Figure 6. CFD grid on aeroshape leeside.
As far as CFD results are concerned, surface distribution of radiative equilibrium temperature for the EFTV-069 run is provided in Figure 7.

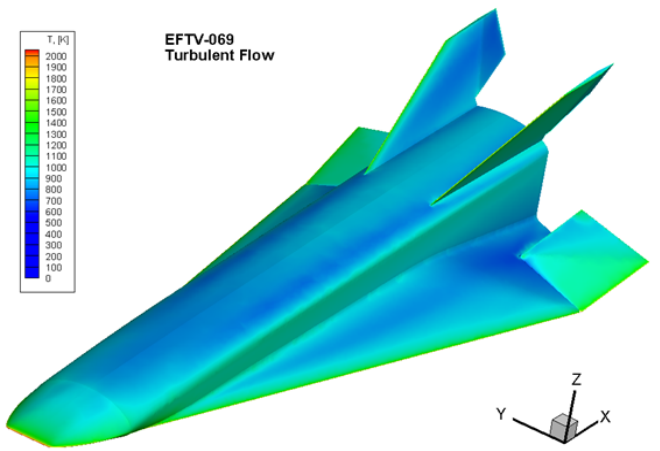

Figure 7. Temperature contours for the EFTV-069 run for turbulent boundary layer.

This figure points out that flow conditions during flight results in large overheating at vehicle sharp leading edges, which represents the most solicited aeroshape parts, as expected. With this in mind, a number of aeroshape crosssections are considered to address EFTV aerothermal loads, see Figure 8.

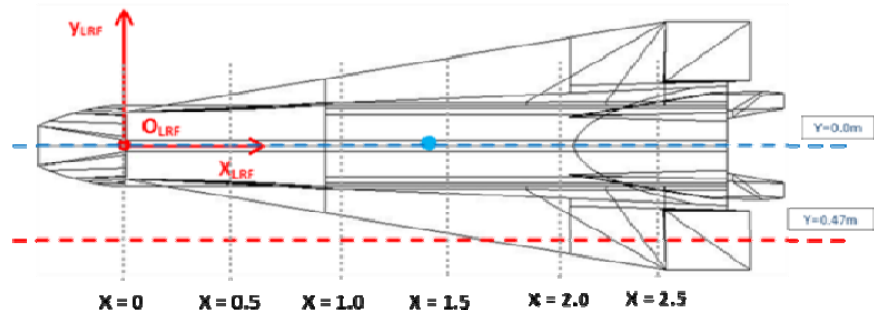

Figure 8. Aeroshape planes and sections considered for both the aeroheating and transition analysis.

Detailed distribution of pressure and convective heat flux distributions at centerline $(\mathrm{Y}=0.0 \mathrm{~m})$ and mid-wing plane $(\mathrm{Y}=0.47 \mathrm{~m})$ are shown from Figure 9 to Figure 12.

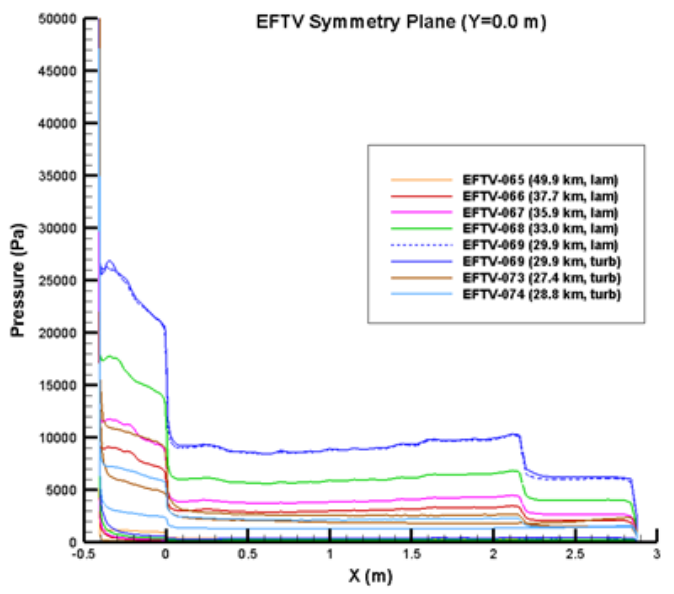

Figure 9. Pressure distributions at EFTV's centerline. 


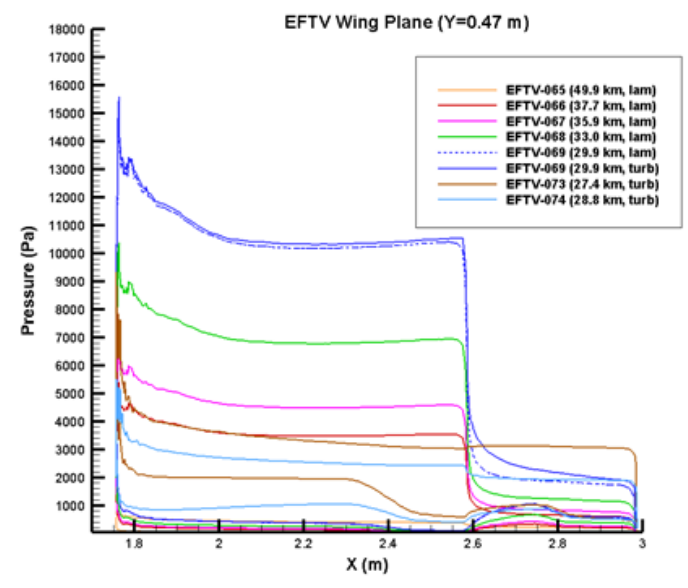

Figure 10. Pressure distributions at section $Y=0.47 \mathrm{~m}$.

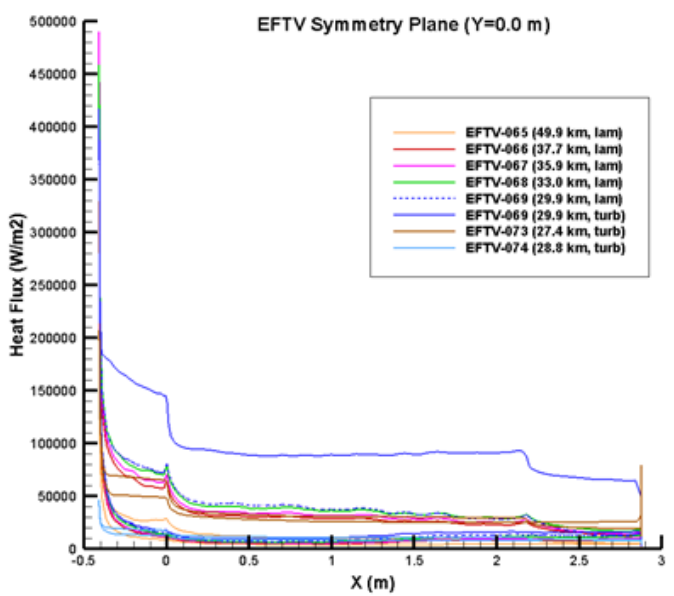

Figure 11. Convective heat flux distributions at EFTV's centerline.

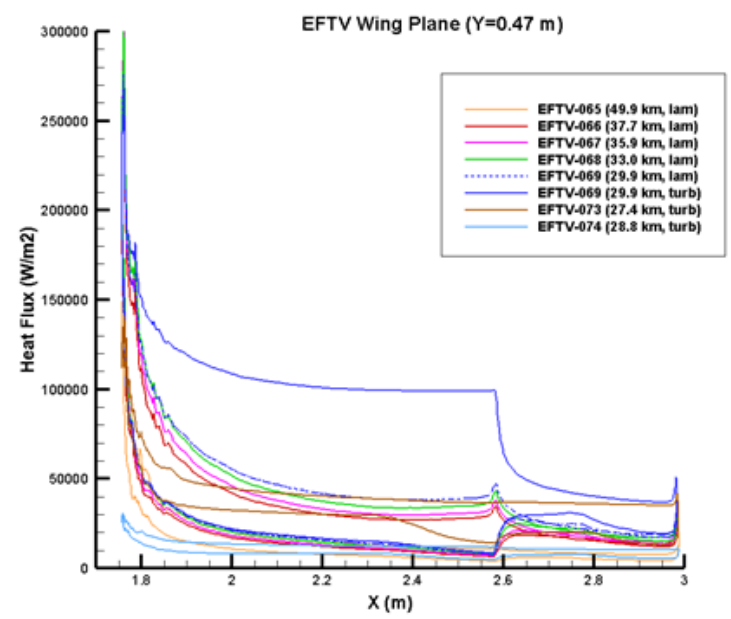

Figure 12. Convective heat flux distributions at $Y=0.47 \mathrm{~m}$.
Results comparisons on cross sections at $\mathrm{X}=0.0 \mathrm{~m}$ and $\mathrm{X}=0.5 \mathrm{~m}$ in terms of convective heat flux distributions are shown in Figure 13 and Figure 14, respectively.

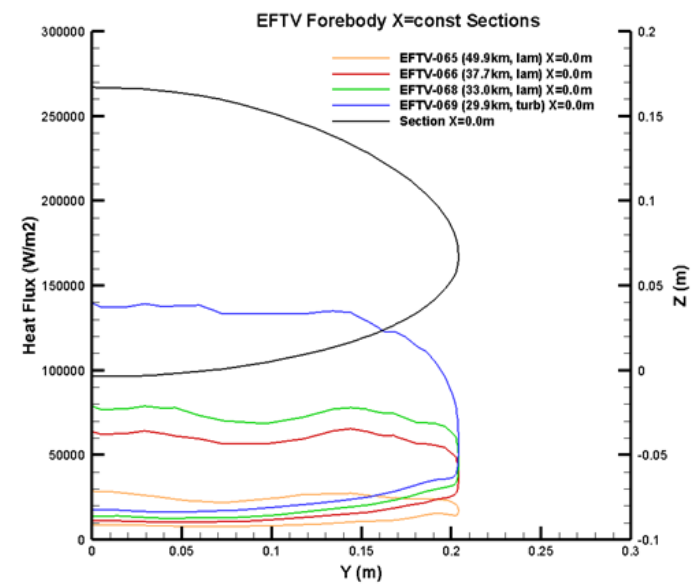

Figure 13. Heat flux distributions on $\mathrm{X}=\mathbf{0 . 0} \mathrm{m}$ cross section.

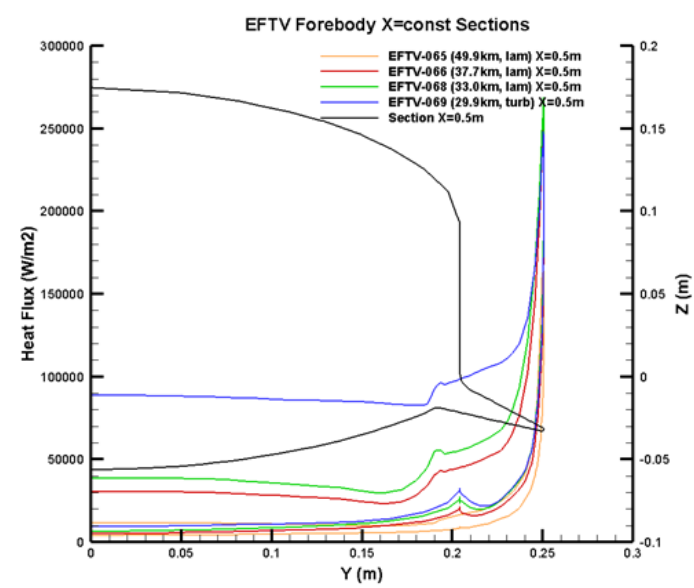

Figure 14. Heat flux distributions on $\mathrm{X}=0.5 \mathrm{~m}$ cross section.

Results comparison between laminar and turbulent boundary layers indicates that heat flux at fuselage leading edge reaches values close to about $500 \mathrm{KW} / \mathrm{m}^{2}$ at peak heating conditions, while $300 \mathrm{~kW} / \mathrm{m}^{2}$ is expected on wing leading edge at both $\mathrm{Y}=0.47 \mathrm{~m}$ and $\mathrm{X}=0.5 \mathrm{~m}$. In particular, CFD results also point out that the flow remains laminar on the leeside of fuselage and wing (i.e., no effect of turbulence), while on vehicle windside roughly a factor two of turbulence is expected.

\section{BOUNDARY LAYER TRANSITION ASSESSMENT}

To estimate the onset and extent of laminar-to-turbulence boundary layer transition, various methods were employed for the EFTV glider [14]. Empirical correlations were not only used to predict the transitional parameters, but also helped in defining the optimal wing leading edge radii. CFD simulations supported the transitional criteria by characterizing the boundary layer at critical points along the vehicle. Similar 
approaches were used to estimate critical heights of perturbations. All of this was finally verified experimentally in a wind tunnel (TsAGI T-116 facility) at representative flight conditions. It helped understanding as well what type of imperfections could be accepted for the final integration and assembly of the flight vehicle [14].

As reported in Ref. [14], in general the correlations for a clean configuration without any perturbation seem to agree with what is observed experimentally in the wind tunnel T-116 at TsAGI. On the windward side, the transition onset starts for the various attitudes around midway whereas no clear transition is detected on the leeward side of the EFTV. The flow pattern on this upper side is quite affected by three-dimensional vortical structures, which render the heat loads quite higher than one would expect from turbulent correlations on a flat plate. The various heights and sizes of perturbations enabled the critical dimension to trigger transition. The subcritical heights for which transition onset was not or hardly changed are in line with the correlations.

We report hereinafter only the laminar-to-turbulence transition results extracted from correlation criteria applied basing on CFD simulations in flight conditions.

Five dimensioning points were selected along the trajectory (see Table 1) to assess the transitional behavior of the boundary layer, i.e. run id 066, 068, 069, 070 and 071. These points represent respectively the highest trajectory point where AoA is set to $12 \mathrm{deg}$ (EFTV-066), the point of maximum nose heat flux (EFTV-068), the lowest trajectory point where AoA is set to 12 deg (EFTV-069), the point of maximum aerodynamic efficiency (EFTV-070), and the point of maximum heat flux (EFTV-071). Starting from the boundary layer properties derived from CIRA's CFD simulations, ESA and CIRA applied various sets of transition criteria to the fuselage $(\mathrm{Y}=0.0 \mathrm{~m})$ and the wing $(\mathrm{Y}=0.47 \mathrm{~m})$ sections at different $\mathrm{X}$-stations $(\mathrm{X}=-0.2$, $0.0,0.5,1.0,1.5,2.0,2.5,2.75 \mathrm{~m}$ ) (see Figure 8).The criterion used to detect boundary layer edge from the (normal-to-wall) profiles of velocity and total enthalpy is $\mathrm{H}_{0 \mathrm{e}}=0.99 \cdot \mathrm{H}_{0}$.

To estimate transition onset location and transition zone length, ESA applied the criteria of Simeonides [14], [15]. These take into account the leading edge bluntness thickness which is defined as twice the leading edge curvature radius. The other approach [14] for transition onset and length determination is based upon the effect of free-stream perturbation on transition onset and the turbulent spot growth parameter $n \sigma$. The latter parameter allows describing the evolution of the intermittency factor $\gamma$ enabling the state and extent of transition at each point.

Based on Mayle's correlations and considering compressibility effects, the free-stream perturbation level $T u$ is estimated indirectly using Simeonides' transition onset [16]. The dependency of the spot growth parameter on this estimated $T u$-level allows then to determine the spot growth parameter and the transitional evolution. For each case, the possible transition is determined at different cross sections in the streamwise direction using the local edge values. By intersecting the local distance from the leading edge with the relative transition start distance, the transition point can be determined. The use of local boundary layer edge properties allows considering indirectly the pressure gradients and other features depending on the local geometry (e.g. aileron deflection). This transition dependence on leading edge bluntness allows also deriving optimal nose and wing leading edge radii while considering also aspects such as integration, manufacturing and integrated heat load. For the nose leading edge, a variation within $1 \mathrm{~mm}$ to $2 \mathrm{~mm}$ radius was preferred to cope with the stagnation heat loads. For the wing leading edges, the CMC parts can go down up to $0.1 \mathrm{~mm}$ radius, whereas one could easily go up to $1 \mathrm{~mm}$ without compromising integration aspects.

Two additional transition criteria were proposed by CIRA [14]. The first criterion, due to Di Cristina, gives the local transition Reynolds number $\mathrm{Re}_{\mathrm{Xt}}$ as a function of the local edge Mach number $M_{e}$ (The effect of wing leading edge is also accounted for in the criterion by means of a function of wing sweep angle $\Lambda)$ [17]. In the case of the EFTV $(\Lambda=80.1 \mathrm{deg})$ the "actual" Reynolds number is largely reduced and this has a beneficial effect on the critical Reynolds number at which laminar-to-turbulence transition starts. The second criterion employed is the one proposed by Berry et al. [18], and was used in the frame of the NASP and X-43A projects for boundary layer transition. It correlates the local transition Reynolds number based on momentum thickness $\operatorname{Re}_{\theta}$ to the local edge Mach number $\mathrm{Me}$, i.e. $\left(\mathrm{Re}_{\theta} / \mathrm{Me}\right) \geq 300 \div 450$.

As far as transition on fuselage centerline is concerned, the outcome of the various correlations is discussed below for both aeroshape wind and leeward side. For the windward side and nose radius of $2 \mathrm{~mm}$, transition was detected according to Simeonides' criteria only as from point EFTV-069 onwards: transition started around 1.52-1.76 m from leading edge (LE) with a transition length of about 1.15 to $1.26 \mathrm{~m}$ (see Figure 16). Transition was predicted complete at the end of fuselage (2.66$3.02 \mathrm{~m}$ from LE). For case 068, beginning of transition was only found with the cone criterion at $2.4 \mathrm{~m}$ but the expansion occurring shortly after in the aft of the fuselage suppressed any further spot growth. Hence, transition could be considered eminent but not present. The prediction of transition extent among the two methodologies varied only with $10 \%$. In case a nose radius of $1 \mathrm{~mm}$ was selected, the transition always started earlier. Already at a higher altitude (point EFTV-068), onset was predicted around $2.2 \mathrm{~m}$ but the transitional zone was only developed to an intermittency of $15 \%$ at the trailing edge. For the point EFTV-069, the onset shifted about $10 \mathrm{~cm}$ upstream to around 1.45 to $1.65 \mathrm{~m}$ from the leading edges. Evidently, transition was also completed before the trailing edge.

For the leeward side, no transition was ever detected for both the $1 \mathrm{~mm}$ and $2 \mathrm{~mm}$ nose radius. From this evaluation, a $2 \mathrm{~mm}$ leading edge was favored for implementation as it delayed transition on the windward side. All the results according to Simeonides' criteria are reported in Figure 15. 


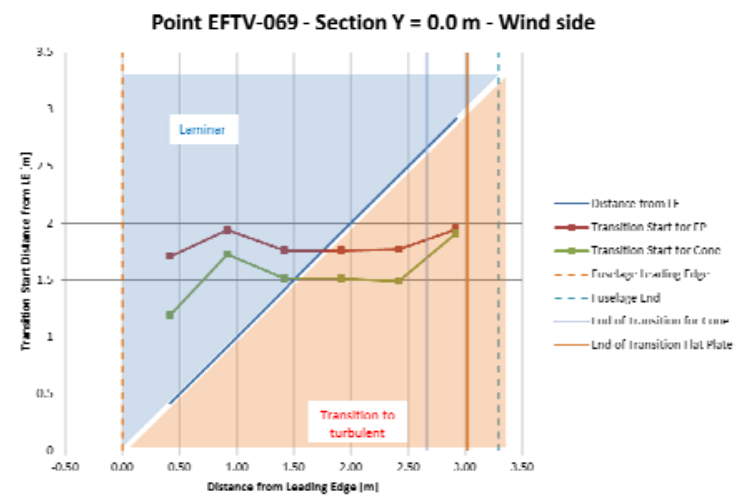

Figure 15. Transition onset estimation according to flat plate and cone correlations of Simeonides.

Di Cristina and Berry criteria predicted also a fully laminar flow on the leeside. On the windside, laminar flow is predicted by Di Cristina's criterion whereas transition is predicted by NASP criterion at the very rear of the fuselage: $2.55 \mathrm{~m}$ from nosetip at $33.06 \mathrm{~km}$ and $2.30 \mathrm{~m}$ from nosetip at $29.93 \mathrm{~km}$. Results are reported in Figure 16 for the section $\mathrm{Y}=0.0 \mathrm{~m}$ (fuselage) where $\mathrm{X}=0$ is located at the nose tip. For the wing, no transition was found on the lee-side in the investigated plane. For the windside, results are strongly dependent on the leading edge radius of curvature: used values were $1.0,0.5$,
0.25 and $0.1 \mathrm{~mm}$. Only data obtained with the flat plate criterion were used.

- $\quad 0.1 \mathrm{~mm}$ radius: starts around $2.16 \mathrm{~m}$ and is practically completed at the end of the wing section with exception of point EFTV-069 were a strong effect of the aileron expansion is seen.

- $0.25 \mathrm{~mm}$ radius: starts around $\mathrm{X}=2.5 \mathrm{~m}$ and only partially completed at trailing edge.

- $0.5 \mathrm{~mm}$ radius: transition is not happening until the very end of the wing section.

- $1 \mathrm{~mm}$ radius: transition never starts.

Hence, $1 \mathrm{~mm}$ radius was finally selected for the design which allowed both easer integration and heat load handling. This result is also confirmed by the Di Cristina's criterion, displayed for the lower altitude case (EFTV-069), see Ref. [14]. Fully laminar flow both at leeside and windside is predicted (the effect of aileron's negative deflection is observed, too), due to the beneficial effect of wing sweep that strongly reduces local Reynolds number.

\begin{tabular}{|c|c|c|c|c|c|c|c|c|c|c|c|c|c|c|c|}
\hline $\begin{array}{l}\text { Trajectory } \\
\text { Point }\end{array}$ & Y Section & \begin{tabular}{|c|} 
Leading \\
Edge Radius
\end{tabular} & Side & \begin{tabular}{|c|} 
Transition \\
Start FP
\end{tabular} & \begin{tabular}{|c|} 
Transition \\
End FP
\end{tabular} & Tu FP & $\begin{array}{c}\text { max } \\
\text { gamma FP }\end{array}$ & \begin{tabular}{|l|} 
Transition \\
Start Cone
\end{tabular} & $\begin{array}{l}\text { Transition } \\
\text { End Cone }\end{array}$ & Tu Cone & $\begin{array}{c}\text { max gamma } \\
\text { cone }\end{array}$ & \begin{tabular}{|c|} 
Trans. \\
Length FP
\end{tabular} & $\begin{array}{c}\text { Trans. Length } \\
\text { Cone }\end{array}$ & $\begin{array}{c}\text { Trans. } \\
\text { Length } 2 \text { FP }\end{array}$ & $\begin{array}{l}\text { Trans. Length } \\
2 \text { Cone }\end{array}$ \\
\hline$[-]$ & [m] & [m] & {$[-]$} & [m] & {$[\mathrm{m}]$} & [\%] & {$[-]$} & [m] & {$[\mathrm{m}]$} & [\%] & {$[-]$} & {$[\mathrm{m}]$} & [m] & [m] & [m] \\
\hline EFTV-066 & 0 & 0.002 & w & NA & NA & NA & NA & NA & NA & NA & NA & NA & NA & NA & NA \\
\hline $\begin{array}{l}\text { EFTV-068 } \\
\end{array}$ & 0 & 0.002 & w & NA & NA & NA & NA & 2.4 & NA & 0.3 & 0.01 & NA & NA & NA & NA \\
\hline EFTV-066 & 0 & 0.001 & w & NA & NA & NA & $\mathrm{NA}$ & NA & NA & NA & NA & NA & NA & NA & NA \\
\hline EFTV-068 & 0 & 0.001 & W & 2.20 & 4.02 & 0.37 & 0.15 & 2.25 & 4.23 & 0.35 & 0.17 & 1.82 & 1.98 & 1.73 & 2.50 \\
\hline EFTV-069 & 0 & 0.001 & w & 1.65 & 2.89 & 0.32 & 1.00 & 1.45 & 2.55 & 0.36 & 1 & 1.24 & 1.1 & 1.10 & 1.05 \\
\hline
\end{tabular}

Table 2. Transition onset and extent predictions [14].
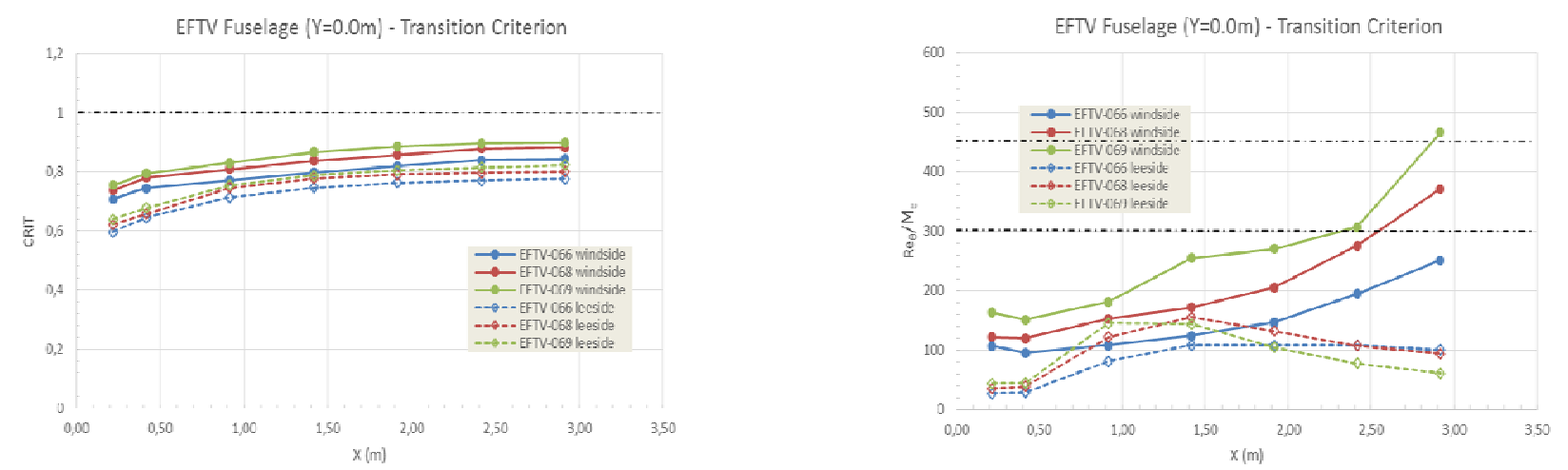

Figure 16. EFTV laminar-to-turbulence natural transition: Di Cristina criterion (top) and X-43A criterion (bottom).

Table 3 provides the comparison concerning the transition starting point for altitudes $37.71,33.06$, and $29.93 \mathrm{~km}$ between CIRA and ESA. Only the windward sides were compared, because no transition was always predicted for the leeward sides. A general agreement is found out, with no transition detected for the first point at $37.71 \mathrm{~km}$, a relative late one for the one at $33.06 \mathrm{~km}$ and clear transition happening only at the lowest altitude. In this case a significant difference is found 
between ESA and CIRA: both criteria used at ESA predict transition starting between 1.5 and $1.75 \mathrm{~m}$ (average of $1.65 \mathrm{~m}$ ), while the ones used at CIRA predict the start much more downstream $(2.3 \mathrm{~m})$. The correlations of ESA take into account the LE-radius and seem to correspond with the experimental values. Later transition points would occur when increasing the LE-radius. This could potentially explain the difference.

\begin{tabular}{|c|c|c|c|c|}
\hline $\begin{array}{c}\text { Trajectory } \\
\text { Point }\end{array}$ & Y Section & Side & $\begin{array}{c}\text { Transition } \\
\text { Start CIRA }\end{array}$ & $\begin{array}{c}\text { Transition } \\
\text { Start ESA }\end{array}$ \\
\hline$[-]$ & {$[\mathrm{m}]$} & {$[-]$} & {$[\mathrm{m}]$} & {$[\mathrm{m}]$} \\
\hline EFTV-066 & 0 & $\mathrm{~W}$ & $\mathrm{NA}$ & $\mathrm{NA}$ \\
\hline EFTV-068 & 0 & $\mathrm{~W}$ & 2.55 & $>2.4$ \\
\hline EFTV-069 & 0 & $\mathrm{~W}$ & 2.3 & 1.65 \\
\hline
\end{tabular}

Table 3: Transition onset prediction comparison [14].

\section{THERMAL DESIGN}

\section{NUMERICAL PROCEDURE}

The vehicle thermal behavior has been preliminary assessed by means of the Finite Element Method (FEM) implemented in the software ANSYS [15-16]. A transient analysis along the computed entry path is performed to evaluate the time dependent temperature of the structure. In synthesis, as also schematically reported in Figure 17, the following procedure has been carried out:

- the available CAD drawing of the vehicle is implemented in

ANSYS Workbench and properly modified, if required;
- the computational mesh for the subsequent analyses is generated;

- the transient thermal analysis is set assuming as boundary condition the convective heat transfer coefficient spatial distribution over the vehicle surface, evaluated in a certain number of flight conditions by means of stationary CFD calculations. These distributions are properly scaled by the stagnation-point heat transfer coefficient variation along the trajectory, normalized with respect to the corresponding reference condition (see Figure 17 ). A radiative dissipation condition is also considered for all the external surfaces;

- static structural computations can be then carried out, if required, in the most critical conditions along the trajectory, assigning as boundary conditions the temperature distributions previously evaluated at selected instants along the trajectory and the pressure distribution resulting from CFD analyses.

As previously mentioned, the boundary condition for the transient thermal analysis has been assigned in terms of the convective heat transfer coefficient, so that the FE numerical code can take into account the effective heat flux entering the structure as the wall temperature increases under the heating process. The stagnation-point convective heat transfer coefficient variation over the trajectory has been obtained from the corresponding convective heat flux profile, estimated by means of the Tauber's [10] relationship throughout the descent flight (see Equation 1, valid assuming an ideal gas condition and a constant specific heat).

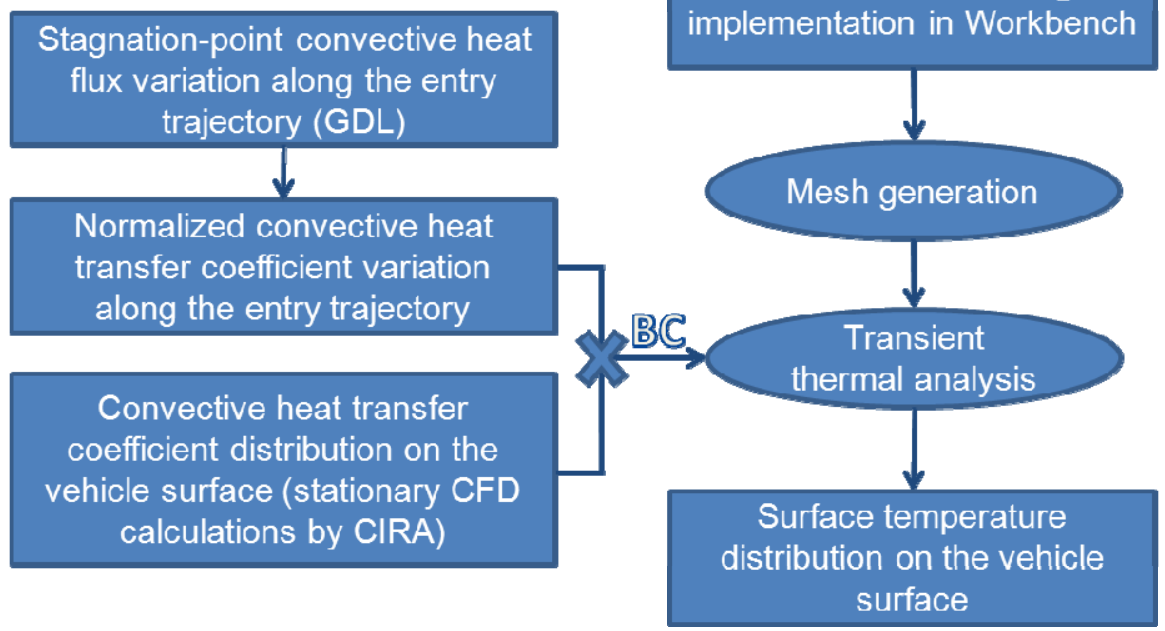

Figure 17. Numerical procedure flow chart 


$$
\begin{aligned}
& \dot{q}=h \cdot\left(T_{0}-T_{w}\right) \approx \frac{\dot{q}_{c w}}{T_{a w}} \cdot\left(T_{a w}-T_{w}\right)= \\
& =\frac{\dot{q}_{h w, e q}}{T_{a w}-T_{w, e q}} \cdot\left(T_{a w}-T_{w}\right)
\end{aligned}
$$

It is clear that the convective heat transfer coefficient at any point of the vehicle surface and at a certain time instant can be obtained multiplying the value of the heat transfer coefficient at the selected spatial point (resulting from the CFD calculation), by the normalized stagnation-point convective heat transfer coefficient along the flight path at the selected time instant.

\section{GENERAL BOUNDARY CONDITION ADOPTED}

As results of the methodology described in the previous section, thermal analysis starts from point 1 to the end of mission in Figure 2, where points representing time instants used to rebuild the trajectory are:

1. fairing ejection at about $82 \mathrm{Km}$;

2. payload release at apogee $(90 \mathrm{Km})$;

3. ESM separation at about $50 \mathrm{Km}$;

4. 6 CFD points: EFTV-065, EFTV-066, EFTV-067, EFTV-068, EFTV-069, EFTV- 073 (see Table 1Errore. L'origine riferimento non è stata trovata.).

Initial temperature condition considered for the whole EFTV's structure is $27^{\circ} \mathrm{C}$ as indicated by DLR-Moraba as the most suitable temperature at fairing opening. Sizing heat fluxes based on hypothesis of laminar-to-turbulence transition at 30 $\mathrm{km}$ altitude (EFTV-069) have been considered, as described in the next section. Uncertainties are also included in margins definition. In particular following hypothesis have been taken into account:

- Laminar flow: 20\% (Reynolds effect due to $1 \mathrm{~km}$ trajectory dispersion, CFD code-to-code error);

- Turbulent flow: $35 \%$ (Reynolds effect due to $1 \mathrm{~km}$ trajectory dispersion, CFD code-to-code error, turbulent modelling error).

\section{NUMERICAL RESULTS}

This section presents the transient thermal analysis results obtained for EFTV applying the boundary conditions described in the previous sections. The main objective of this update is to assess the effect of $1 \mathrm{~mm} \mathrm{ZrO} 2$ coating on the temperature of the structure. Secondly, the applications of margins and transition on heat fluxes on the expecting temperature evolution must be assessed as well.
Different materials are considered in the model as shown in Figure 18 and Figure 19. Preliminary materials considered are summarized in Table 4.

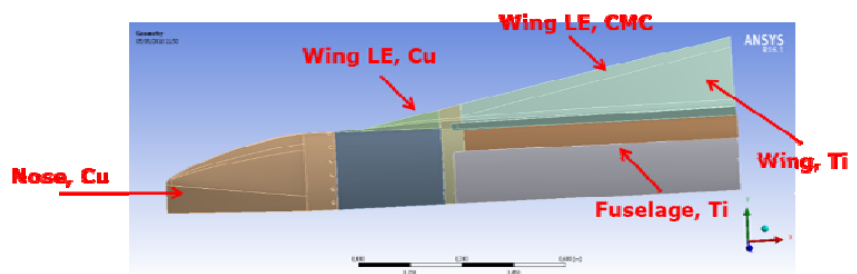

Figure 18: Material definition for different component of leeside in the updated FEM.

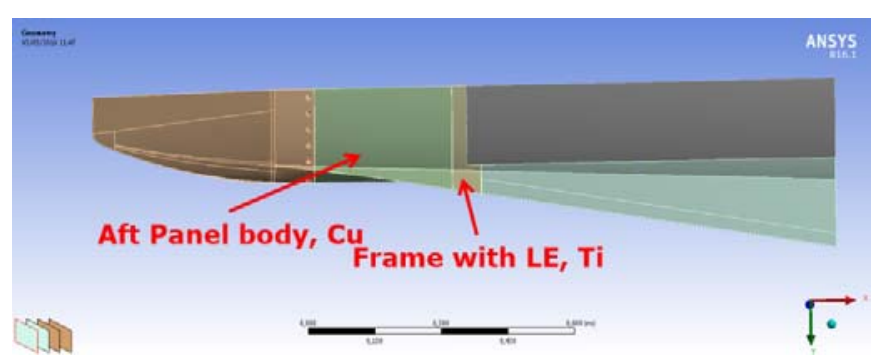

Figure 19: Material definition for different component of windside in the updated FEM.

\begin{tabular}{||c|c|c|c||}
\hline \multicolumn{3}{|c||}{ EFTV } \\
\hline \hline Nose & Fuselage & Wing & Wing LE \\
\hline \hline Copper & Ti-Alloy & Ti-Alloy & $\begin{array}{c}\text { C/C-SiC / } \\
\text { Copper } \\
\text { Ti (linked to frame 1) }\end{array}$ \\
\hline
\end{tabular}

Table 4: Preliminarily material selection for the main EFTV structural components.

Four different finite element models have been initially considered:

MODEL 1: 3D mesh with $1 \mathrm{~mm}$ zirconia coating on leeside and windside (580k nodes) Figure 20

- 6 CFD input (transition plus margin) are here considered: 065- lam; 066 - lam; 067-lam; 068- lam; 069 - turb; 073-turb.

MODEL 2: 3D mesh with $1 \mathrm{~mm}$ zirconia coating only on nose and windside (400k nodes) Figure 21

- 6 CFD input (transition plus margin) considered: 065lam; 066 - lam; 067-lam; 068- lam; 069 - turb; 073turb. 
MODEL 3: 3D mesh with $1 \mathrm{~mm}$ zirconia coating only on nose and windside (400k nodes)

- 6 CFD input (transition no margin) considered: 065lam; 066 - lam; 067-lam; 068- lam; 069 - turb; 073turb.

MODEL 4: 3D mesh with $1 \mathrm{~mm}$ zirconia coating on nose and windside (400k nodes)

- 5 CFD input (fully laminar no margin) considered : 065- lam ; 066 - lam; 067-lam; 068- lam; 069 - lam

Figure 22 shows the temperature contours at the peak heating condition applying the CFD heat transfer coefficient evaluated as previously described. Contour plots clearly show that zirconia coatings, C/C-SiC and copper components on EFTV (having maximum service temperatures, respectively, in the order of $2400^{\circ} \mathrm{C}, 1600^{\circ} \mathrm{C}$ and $800^{\circ} \mathrm{C}$ ) would widely survive the aerothermal environment in these conditions. On the other hand, it can be noted that the maximum temperatures on the titanium structures slightly exceed their upper working temperature limits $\left(600{ }^{\circ} \mathrm{C}\right.$ - Figure 23 to Figure 25$)$. This is attenuated by coating the leeside except for a titanium leading edge linked to the frame 1 (see results in Table 5). Figure 22 shows the temperature distribution, at the peak heating condition, for structural components of the EFTV. Such temperature overshoot can be in principle redistributed inside the vehicle structure through a future thermal structural optimization.

\begin{tabular}{ccccc}
\hline \hline & Lat Frame 1 & Wing lee & Lee panel 2 & Lee panel 1 \\
\hline FEM 1 & 840 & 660 & 600 & 500 \\
\hline FEM 2/3/4 & 1020 & 695 & 740 & 600 \\
\hline \hline
\end{tabular}

Table 5. Comparison FEM 1 and FEM 2. Maximum temperature on Titanium components.

Figure 23 to Figure 25 show the relative effect of coating and margin highlighting always a non-negligible effect for the different vehicle components. In particular, the relative importance of these two effects seem to vary according to the different components, but it always varies between 10 and $15 \%$ w.r.t maximum temperature over time.

Moreover, aerothermal boundary conditions play a key role on the thermal response of the structure. In order to assess the effect of turbulent to laminar transition thermal response of FEM 4 have been compared to those of FEM 3 showing again a non-negligible effects on temperature of different components.

Figure 26 to Figure 29 show on the same plots the thermal response of FEM 2 as well as FEM 3 and FEM4 in order to appreciate the relative effects of applying margin and transition on heat fluxes. Again the relative importance of these two effects seem to vary according to the different components, but it always varies between 10 and $15 \%$ w.r.t maximum temperature over time
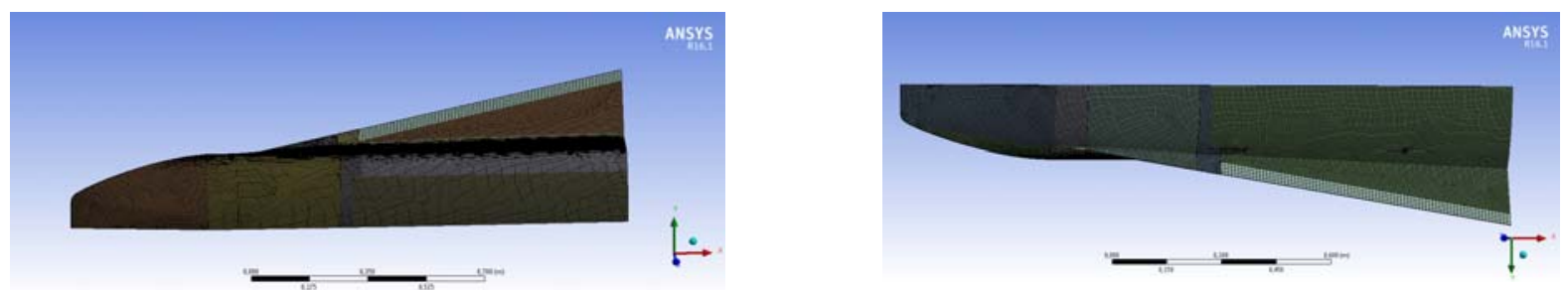

Figure 20. Finite Element Model 1 Mesh
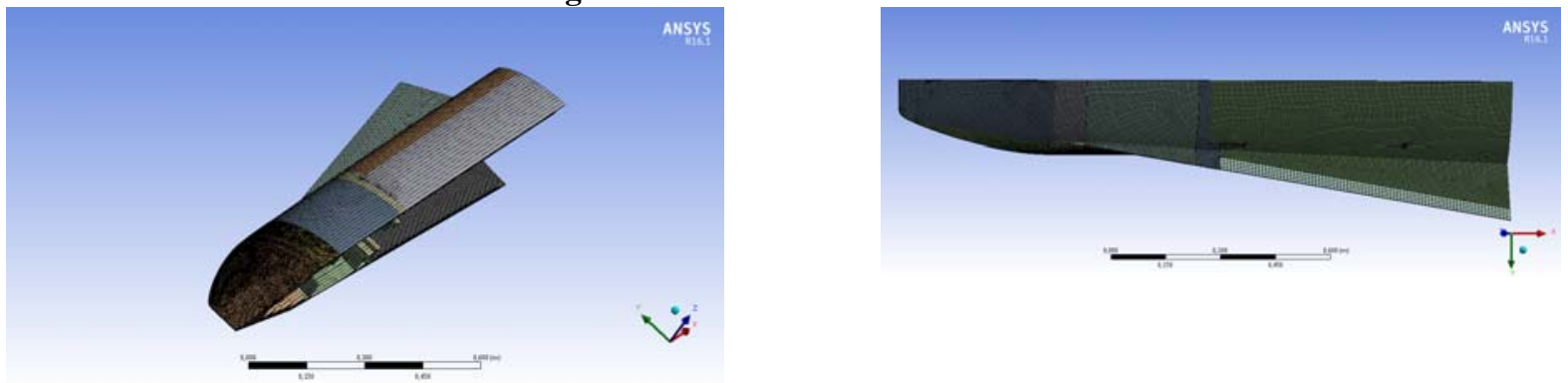

Figure 21. Finite Element Model 2 -3 -4 Mesh 

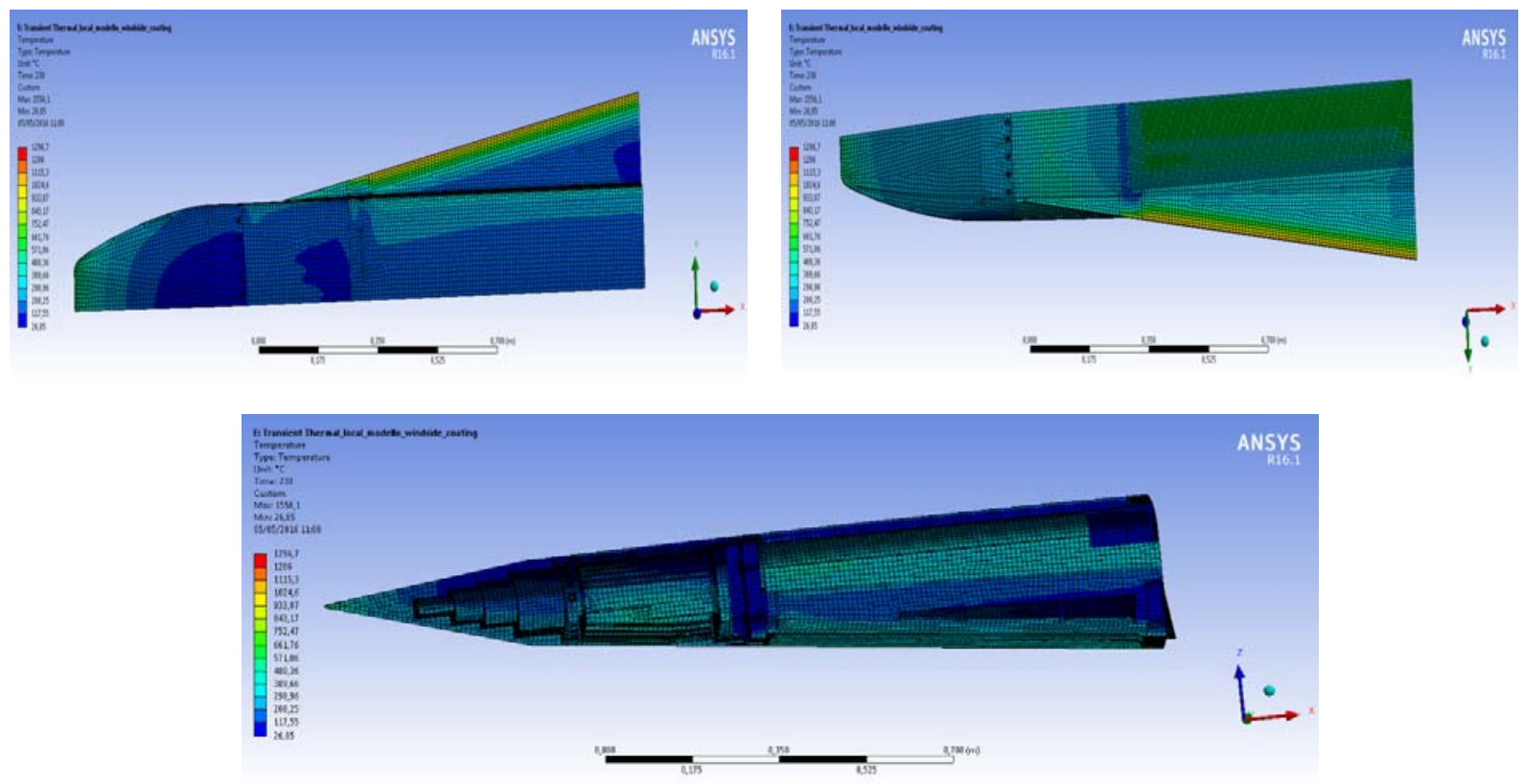

Figure 22. Temperature distribution, at the peak heating condition for structural components of the EFTV
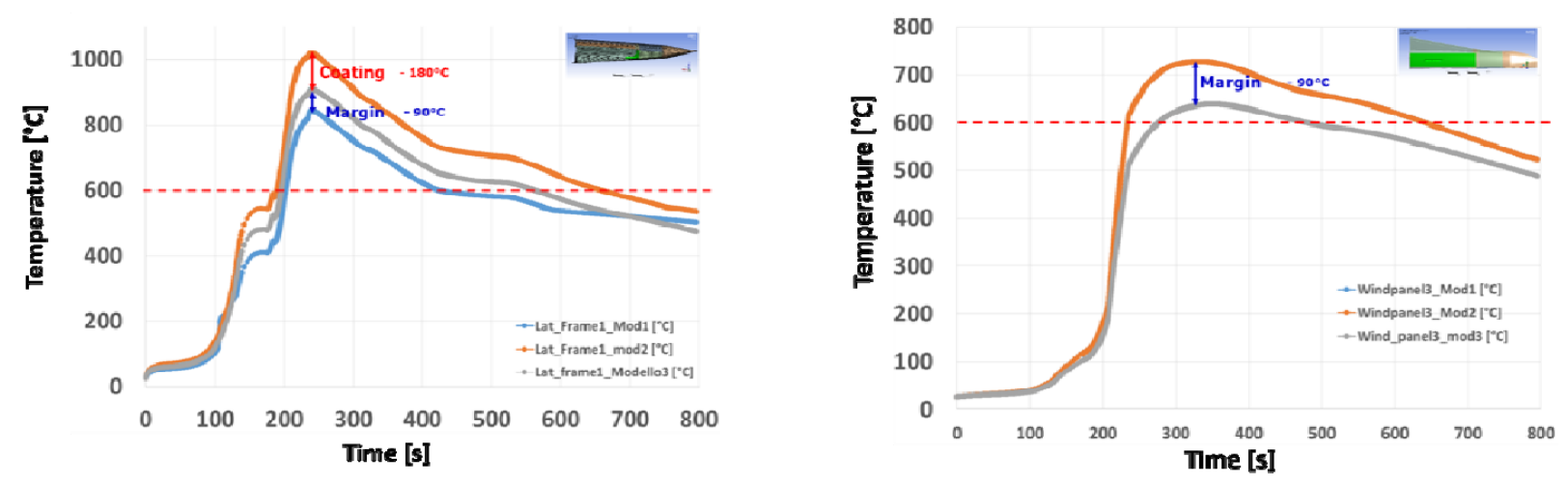

Figure 23: Model 1-2-3. Coating and heat flux margin effect on Lat_Frame1 and windpanel3
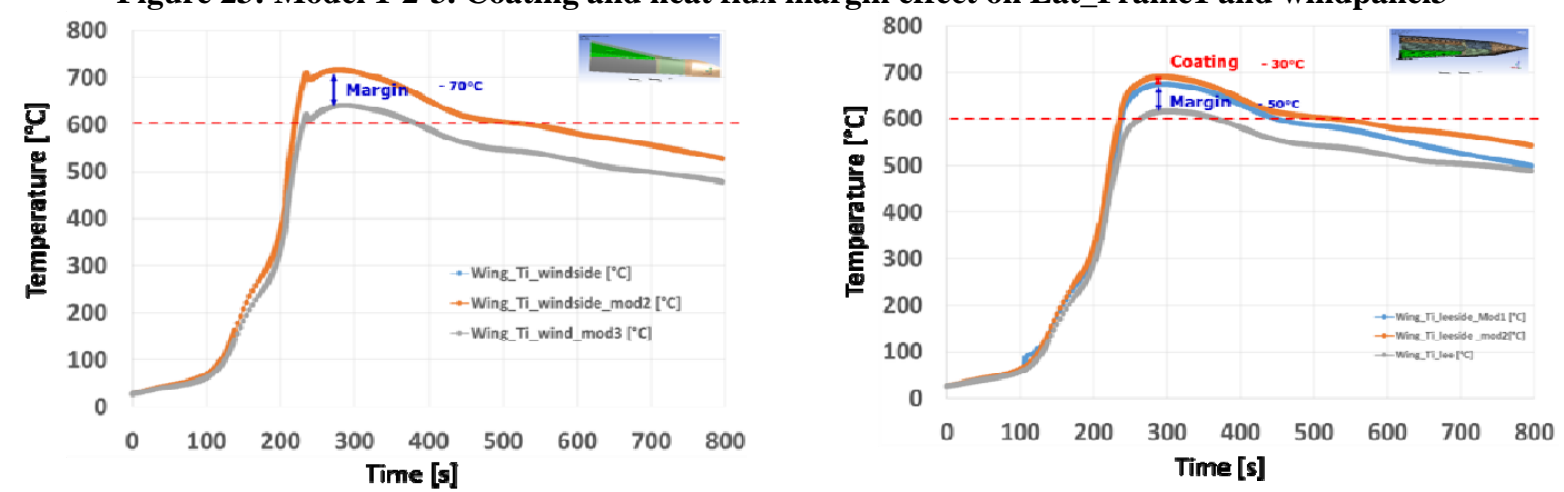

Figure 24: Model 1-2-3. Coating and heat flux margin effect on the wing windside and on the wing leeside 

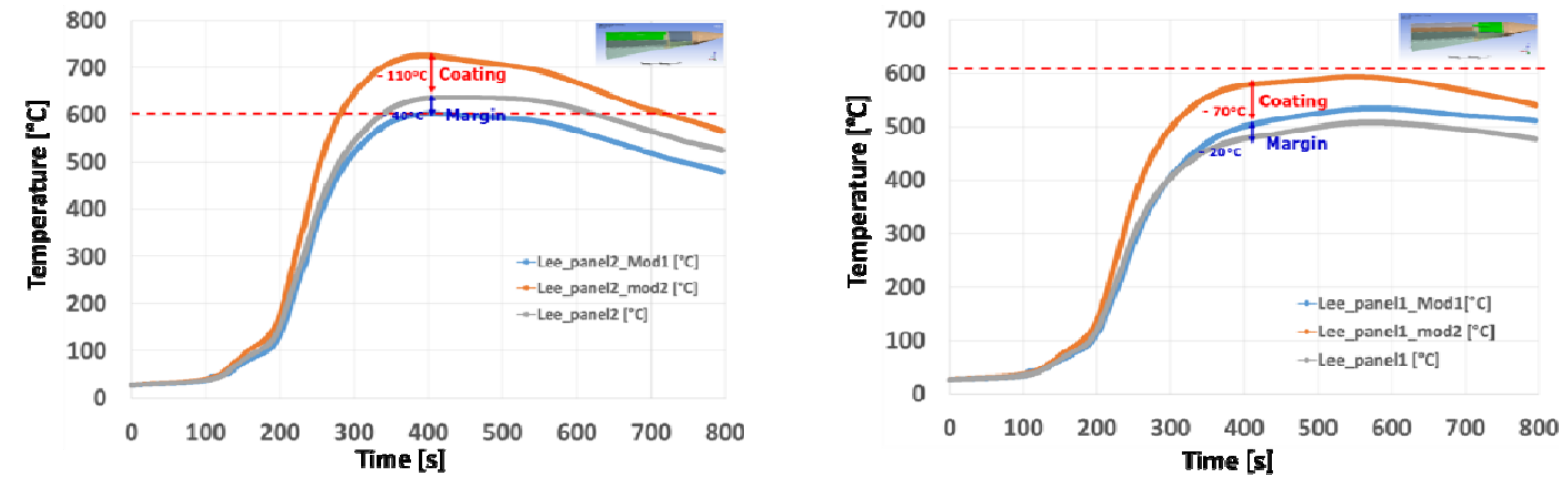

Figure 25: Model 1-2-3. Coating and heat flux margin effect on lee panel 2 and lee panel 1
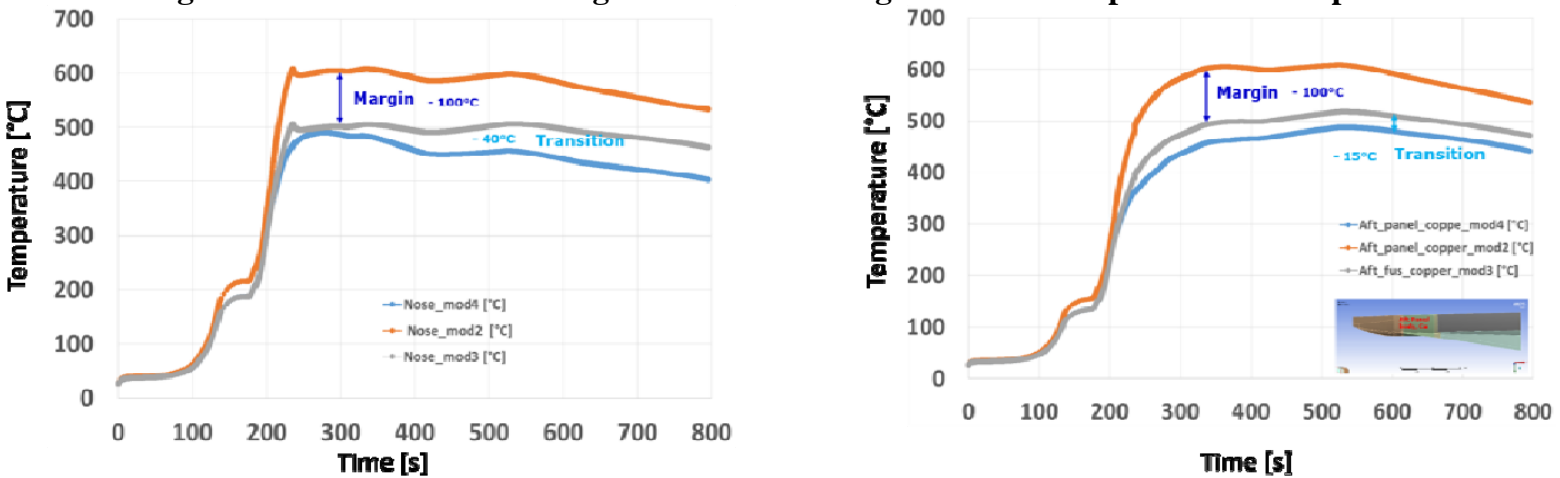

Figure 26: Model 2 - 3 -4 Effect of transition and heat flux margin on temperature on the nose
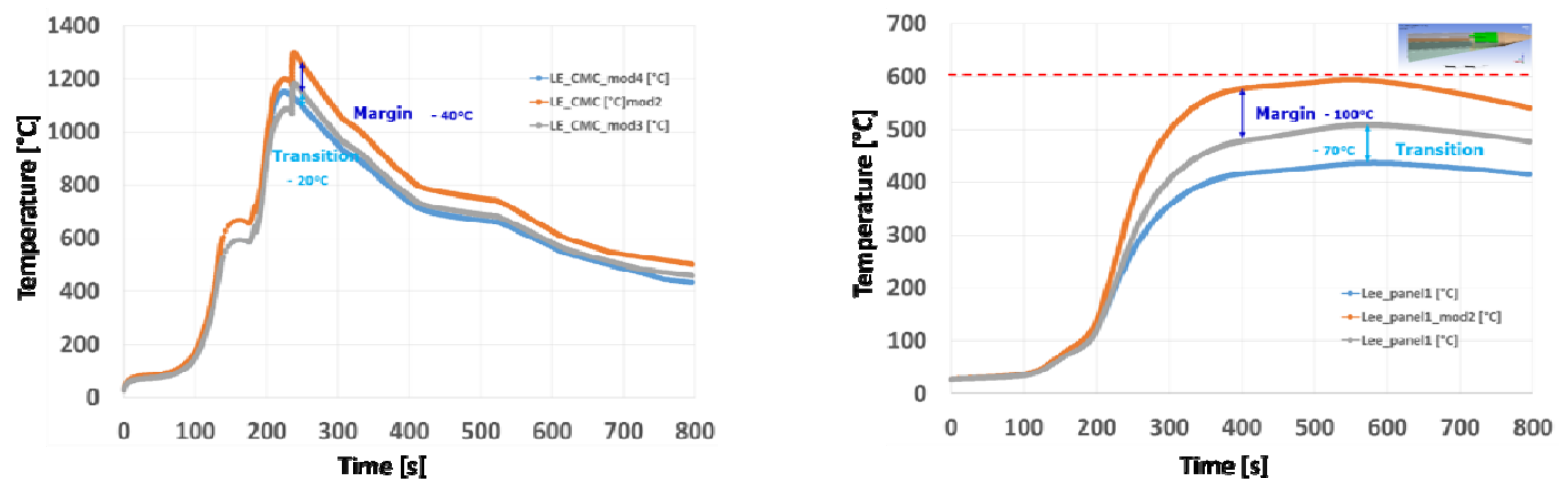

Figure 27: Model 2 - 3 -4. Effect of transition and heat flux margin on temperature on the CMC leading edge and lee panel 1
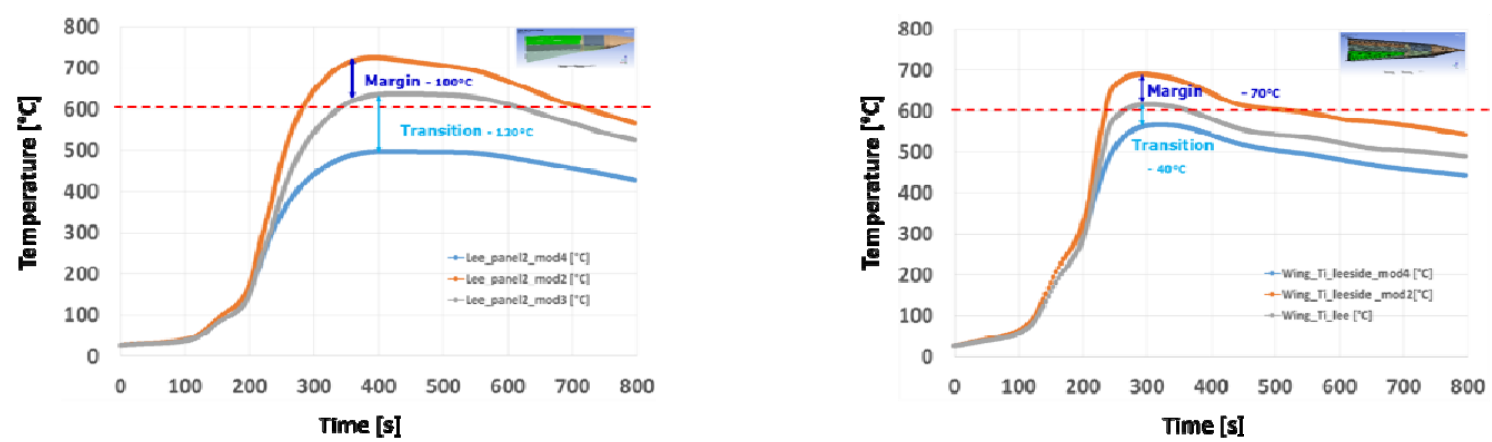

Figure 28: Model 2 - 3-4 Effect of transition and heat flux margin on temperature on lee panel 2 and wing leeside 

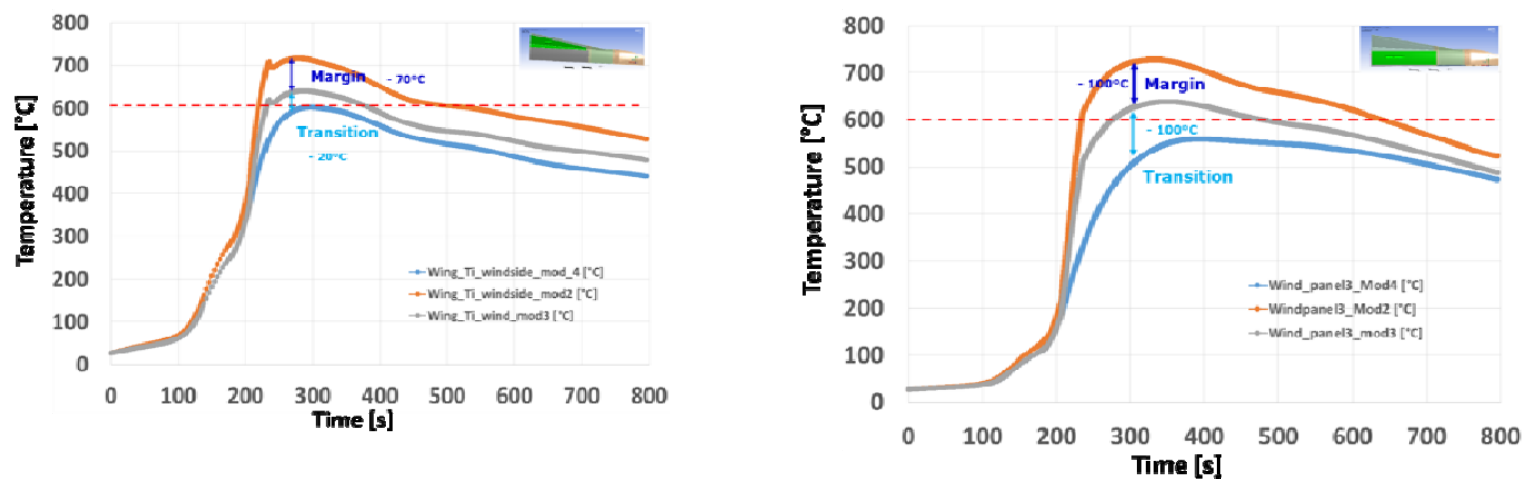

Figure 29: Model 2 - 3-4 Effect of transition and heat flux margin on temperature on wing windside and windpanel 3

It is possible to state that an advisable Thermal Protection System (TPS) for the updated aerothermal environment (transitional fluxes with margin) would have:

- A thicker Zirconia coating on the windside (expecting about $80^{\circ} \mathrm{C}$ decrease each $0,5 \mathrm{~mm}$ - see Figure 23 Figure 24 , Figure $25-$ i.e. $1,5 \mathrm{~mm}$ or $2 \mathrm{~mm}$ is needed)

- Keep $1 \mathrm{~mm}$ of Zirconia coating on the leeside.

- No Titanium leading edges, copper is suggested.

It can be finally concluded that big temperature variations are observed according to different aerothermal environment considered. Therefore, aerothermal environment must be frozen to properly design the final TPS for the EFTV.

\section{CONCLUSIONS}

Aero-thermal simulations presented in the paper are not definitive. Indeed, they have been performed on a sizing reference trajectory that is not the final one and assuming a vehicle mass of $350 \mathrm{~kg}$. The thermal analysis will be of course repeated once the configuration and the aerothermal environment will be frozen. However, with current hypotheses it can be concluded that a proper thermal model has been realized for the EFTV structure on the basis of aero-thermal loads estimated along the flight path. Zirconia coating guarantees a relatively large surface emissivity and a suitable thermal protection for the underlying materials. Copper seems to be adequate for the EFTV nose and the first part of the wing leading edge, considering its ability to work as a heat sink. Copper structures and titanium structures on EFTV can withstand the aerothermal environment except for limited spots, requiring a proper thermal structural optimization. Thermalstructural design is still ongoing and a numerical analysis campaign will be performed on the basis of an updated structural configuration, flight trajectory and aerothermal environment.

\section{ACKNOWLEDGMENTS}

This work is performed within the 'High Speed Experimental Fly Vehicles - International' (HEXAFLY-INT) project fostering International Cooperation on Civil HighSpeed Air Transport Research. HEXAFLY-INT, coordinated by ESA-ESTEC, is supported by the EU within the $7^{\text {th }}$ Framework Program Theme 7 Transport, Contract no.: ACP3-GA-2014620327. The project is also supported by the Ministry of Industry and Trade, Russian Federation. Further information on HEXAFLY-INT can be found on http://www.esa.int/techresources/hexafly_int.

\section{REFERENCES}

[1] Steelant J., 'Achievements Obtained for Sustained Hypersonic Flight within the LAPCAT Project', 15th AIAA International Space Planes and Hypersonic Systems and Technologies Conference, 28/04- 01/05-2008, Dayton, Ohio, USA, AIAA2008-2578.

[2] Steelant, J., Varvill R., Defoort S., Hannemann K. and Marini M., 'Achievements Obtained for Sustained Hypersonic Flight within the LAPCAT-II Projet', $20^{\text {th }}$ AIAA International Space Planes and Hypersonic Systems and Technologies Conference, AIAA-2015-3677, 5-8 July, Glasgow, Scotland. 2015.

[3] Steelant J., 'ATLLAS: Aero-Thermal Loaded Material Investigations for High-Speed Vehicles', $15^{\text {th }}$ AIAA International Space Planes and Hypersonic Systems and Technologies Conference, 28/04-01/05-2008, Dayton, Ohio, USA, AIAA-2008-2582.

[4] Steelant J., Dalenbring M. ., Kuhn M., Bouchez M. and von Wolfersdorf J., 'Achievements obtained within the ATLLAS-II Project on Aero-Thermal Loaded Material Investigations for High-Speed Vehicles', 21st Int. Space Planes and Hypersonic Systems and Technology Conference, AIAA-2017-xxxx, 6-9 March 2017, Xiamen, China, submitted.

[5] Steelant J., Langener T., Hannemann K., Riehmer J., Kuhn M., Dittert C., Jung W., Marini M., Pezzella G., Cicala M. and Serre L., 'Conceptual Design of the High-Speed Propelled Experimental Flight Test Vehicle HEXAFLY', $20^{\text {th }}$ AIAA International Space Planes and Hypersonic Systems and 
Technologies Conference, AIAA-2015-3539, 5-8 July, Glasgow, Scotland. 2015.

[6] Pezzella, G., Marini, M., Reimann, B., Steelant, J., "Aerodynamic Design Analysis of the Hexafly-INT Hypersonic Glider", $20^{\text {th }}$ AIAA International Space Planes and Hypersonic Systems and Technologies Conference, Glasgow, Scotland, 6-9 July 2015. AIAA-2015-3644.

[7] Favaloro, N., Pezzella, G., Carandente, V., Scigliano, R., Vitale, A., Rispoli, A., Steelant, J., "Design Analysis of the High-Speed Experimental Flight Test Vehicle HEXAFLYInternational", $20^{\text {th }}$ AIAA International Space Planes and Hypersonic Systems and Technologies Conference, Glasgow, Scotland. 6-9 July 2015. AIAA 2015-3607.

[8] Scigliano R., Pezzella G., Marini M., Di Benedetto S., Steelant J., "Aerothermal Design of the Hexafly-INT Glider", AIAA2016-5627, AIAA Space 2016 Conference, Long Beach, California, USA, 13-16 September 2016.

[9] J. Steelant, V. Villace, M. Marini, G. Pezzella, B. Reimann, S.L. Chernyshev, A.A. Gubanov, V.A. Talyzin, N.V. Voevodenko, N.V. Kukshinov, A.N. Prokhorov, A.J. Neely, C. Kennell, D. Verstraete, D. Buttsworth, "Numerical and Experimental Research on Aerodynamics of High Speed Passenger Vehicle within the Hexafly-Int Project". 30 Congress of International Council of the Aeronautical Sciences. ICAS 2016. DDC Daejeon Korea. September 25-30, 2016.

[10] G. Pezzella, S. van Brummen, J. Steelant, "Assessment of Hypersonic Aerodynamic Performance of the EFTV-ESM Configuration in the Framework of the Hexafly-Int Research Project", $8^{\text {th }}$ European Symposium on Aerothermodynamics for Space Vehicles. 2-6 March 2015. Lisbon. Portugal. European Space Agency.

[11] E.V. Zoby, "Empirical Stagnation-Point Heat-Transfer Relation In Several Gas Mixtures At High Enthalpy Levels". NASA TN D-4799. OCTOBER 1968.

[12] Prabhu, D. K., "System Design Consraints - Trajectory Aerothermal Environments". Paper presented at the RTO AVT Lecture Series on "Critical Technologies for Hypersonic Vehicle Development”, held at the von Kármán Institute, Rhode-St-Genèse, Belgium, 10-14 May, 2004, and published in RTO-EN-AVT-116.

[13] Marini M., Pezzella G., Schettino A., Di Benedetto S., Villace V., Steelant J., Gubanov A., Voevodenko N., Reimann B., Walton C., "Numerical and Experimental Aerodynamic Characterization of the HEXAFLY-INT Hypersonic Glider", AIAA-2017-2316, $21^{\text {st }}$ AIAA International Space Planes and Hypersonic Systems and Technologies Conference, Xiamen, China, 6-9 March 2017.

[14] Steelant J., Passaro A., Villace V., Gubanov A., Ivanyushkin D., Shvalev Y., Voevodenko N., Marini M., Di Benedetto S., "Boundary Layer Transition Assessment on a Slender HighSpeed Vehicle", AIAA-2017-2133, $21^{\text {st }}$ AIAA International Space Planes and Hypersonic Systems and Technologies Conference, Xiamen, China, 6-9 March 2017.

[15] Simeonides G. A., " Correlation of Laminar-Turbulent Transition Data over Flat Plates in Supersonic/Hypersonic Flow including Leading Edge Bluntness Effects', Shock Waves (2003) 12: 497-508.

[16] Mayle R. E., 'The Role of Laminar-Turbulent Transition in Gas Turbine Engines', Journal of Turbomachinery, Vol. 113, 1991, pp. 509-536.
[17] Di Cristina V., 'Three-Dimensional Laminar Boundary-Layer Transition on a Sharp 8-deg Cone at Mach 10', AIAA Journal, Vol. 8, No. 5, May 1970, p. 855.

[18] Berry S. et al., 'Boundary Layer Transition on X-43A', $38^{\text {th }}$ AIAA Fluid Dynamics Conference, Seattle WA, USA, 23-26 June 2008: AIAA-2008-3736.

[19] ANSYS Inc., Thermal analysis guide, Release 16.1, 2015.

[20] ANSYS Inc., Structural analysis guide, Release 16.1, 2015. 